\title{
Effect of oral contraceptive pills on rheumatoid arthritis disease activity in women: A randomized clinical trial
}

\author{
Leila Amini ${ }^{1}$, Mehri Kalhor*2 ${ }^{* 2}$ Anoushe Haghighi ${ }^{3}$, Naiemeh Seyedfatemi $^{4}$, Fatemah Hosseini ${ }^{5}$ \\ Received: 7 Feb 2017 \\ Published: 20 July 2018
}

\begin{abstract}
Background: Rheumatoid arthritis is one of the most common autoimmune diseases. Because immunological changes can be induced by steroid hormones, it seems that oral contraceptive pills can affect the severity of the disease. In this study, we examined the effect of oral contraceptive pills on rheumatoid arthritis activity in women.

Methods: This blinded randomized clinical control trial was performed in the selected rheumatology centers in Tehran, Iran, in 2011. A total of 100 women with rheumatoid arthritis were included (50 in the intervention and 50 in the control groups), and those in the intervention group took oral contraceptive pills intermittently for 8 weeks. Disease activity was measured at 1 and 9 weeks based on DAS-28, which includes the number of tender joints, number of swollen joints, ESR, and GH. Data were analyzed using SPSS-16, and significance level was set at $\mathrm{p} \leq 0.05$. This study was registered in IRCT (number: 138904224364N1) and all interventions were done after receiving confirmation from the Ethical Committee of Tehran University of Medical Sciences (Code: 250/ 6441).

Results: After administering oral contraceptive pills to the intervention group, we found significant differences between the 2 groups in disease activity and severity scores $(\mathrm{p}=0.04)$. Intervention group showed lower swollen joints score $(\mathrm{p}=0.02)$, lower joint tenderness score $(\mathrm{p}=0.02)$, and lower general health score $(\mathrm{p}=0.001)$ than the control group.

Conclusion: According to the results of this study, oral contraceptive pills can improve rheumatoid arthritis activity and severity. As these pills are used for contraception, women with rheumatoid arthritis can benefit from both effects of these pills.
\end{abstract}

Keywords: Oral contraceptive pill, Disease activity, Rheumatoid arthritis, Autoimmune diseases, Contraception

Copyright $\odot$ Iran University of Medical Sciences

Cite this article as: Amini L, Kalhor M, Haghighi A, Seyedfatemi N, Hosseini F. Effect of oral contraceptive pills on rheumatoid arthritis disease activity in women: A randomized clinical trial. Med J Islam Repub Iran. 2018 (20 July);32:61. https://doi.org/10.14196/mjiri.32.61

\section{Introduction}

Rheumatoid arthritis (RA) is one of the most common autoimmune diseases of connective tissue and is considered as a rheumatic disease. Women, especially in the third to the fifth decades of life, are affected by RA 3 times more than men. RA prevalence is about $0.8 \%$ to $1 \%$ $(1,2)$. According to the World Health Organization report in 2009, RA prevalence in Iran is about $0.34 \%$, which is similar to other Asian countries and lower than Western countries $(3,4)$. Eventually, rheumatoid arthritis can influence different aspects of life, especially physical and psychological dimensions, which can impair the quality of patient's life $(5,6)$. Pregnancy, especially unwanted pregnancy, in these women is an important concern. Because affected women have disabilities in var-

Corresponding author: Mehri Kalhor, mkalhor20@gmail.com

1. Department of Reproductive Health, School of Nursing \& Midwifery, Iran University of Medical Sciences, Tehran, Iran.

2. School of Nursing \& Midwifery, Tehran University of Medical Sciences, Tehran, Iran. 3. Department of Internal Medicine, School of Medicine, Iran University of Medical Sciences, Tehran, Iran.

4. Nursing Care Research Center (NCRC), Iran University of Medical Sciences, Tehran, Iran.

5. Department of Biostatistics, School of Public Health, Iran University of Medical Sciences, Tehran, Iran. ious degrees, they receive health care and family planning services less than they should (7). On the other hand, pregnancy is more complicated in these women because of limitations and problems associated with rheumatoid arthritis. Thus, one of the most important issues in women, especially those with chronic medical diseases such as rheumatoid arthritis, is contraception. Some studies have shown that oral contraceptive pills (OCPs) have a positive effect on rheumatoid arthritis disease activity (8).

It seems that all family planning methods, even intrauterine devices, can be used in patients with RA who are not receiving immunosuppressive therapy. However, still oral contraceptive pills are the best and most effective choice that may have a positive effect on RA development

$\uparrow$ What is "already known" in this topic:

Rheumatoid arthritis is one of the most common inflammatory diseases. Sex hormones can apply some immunological changes, so it seems they may affect the rheumatoid arthritis disease activity.

$\rightarrow$ What this article adds:

Hormones in oral contraceptive pills can reduce rheumatoid arthritis disease activity and severity among women in reproductive age. 
(9). As hormones can apply some immunological changes and rheumatoid arthritis is an autoimmune disease, it is likely that hormones included in oral contraceptive pills can reduce the disease activity and severity $(10,11)$.

Despite years of study on the effects of sex hormones and oral contraceptives pills on RA, much controversy still exists about their positive effects, and thus the effects of oral contraceptives cannot be conclusively confirmed $(12,13)$. Chen et al. (2014) indicated that OCPs use cannot prevent RA onset but can protect the patient's disease severity progression (4). However, Doran et al. (2004) believed OCPs exposure, especially in earlier years of life, can play a prominent role in protection against RA development (7). Thus, it is recommended that more studies be conducted on this subject, especially in communities of different races $(12,13)$. As no study has been performed in this field in Iran, in this study, we examined the effect of oral contraceptive pills on rheumatoid arthritis activity in Iranian women of reproductive age.

\section{Methods}

\section{Patients}

This randomized clinical control trial was performed on 100 women with rheumatoid arthritis (50 women in the intervention and 50 in the control groups graded according to the American Rheumatism Association criteria) who referred to the rheumatology clinics of Shariati and Rasool Akram hospitals in Tehran, Iran, in 2011. Consecutive sampling method was used and women who met the inclusion criteria were allocated to 2 study groups using random block size of 2 ( 50 women in each group). Women with any mental and physical problems (except rheumatoid arthritis), pregnancy, or women with any OCPs taking contraindications were not included in the study.

\section{Intervention and assessment}

Informed consent was obtained from all participants and they were provided with consultation for family planning (The registry code: IRCT $138904224364 N 1$; ethical code: 250/6441). Those women who wanted to choose OCPs as contraception method and had no contraindication for the hormones were included in the intervention group. Women in the control group chose non-hormonal methods for contraception. As these women had to take OCPs for con- traception, the control group could not receive placebo instead of OCPs due to risk of pregnancy. Before any intervention, women in the 2 study groups were assessed for disease activity using DAS-28 international tools by an expert rheumatologist. DAS-28 consists of 3 parts: (1) clinical, including the number of swollen joints and tenderness joints; (2) laboratory test, including erythrocyte sedimentation rate; and (3) general health, or patient's global assessment of disease activity during the last 7 days on visual analogue scale of $0-100 \mathrm{~mm}$ scaled ruler. The general scope of the score in this tool is between 0 to 10 . Scores lower than 3.2 are considered as mild disease activity, the scores between 3.2 and 5.1 as average disease activity, and those higher than 5.1 as severe disease activity (14). Then, low dose OCPs (Iran Hormone Co. contains 0.03 milligrams ethinyl estradiol and 0.15 milligrams levonorgestrel) were given to the intervention group. Women started taking OCPs during the first 5 days of their menstrual cycles and continued for 4 weeks. Then, OCPs were discontinued for 1 week but administered again in the following 4 weeks. During these 9 weeks, women were followed weekly to ensure that they were taking OCPs correctly or to detect any probable side effects. Women in the 2 groups were treated with the same drug regimen for their rheumatologic complications. The control group did not receive any hormonal intervention. The same rheumatologist repeated the disease activity assessment for both groups after 9 weeks.

\section{Statistical analysis}

Data were analyzed using SPSS software 14 and were reported as mean \pm SD or frequency and percentage. For quantitative data, Kolmogorov-Smirnov test was used before statistical analysis to ensure data normality. Then, data were compared with student $t$ test and paired $t$ test. Chi-square test was used to analyze qualitative data and significance level was set at $\mathrm{p}<0.05$.

\section{Results}

A total of 100 women participated in the study (50 in the intervention and 50 in the control groups). The mean \pm SD age of women in the OCPs and control groups were $38.48 \pm 7.47$ and $40.58 \pm 8.19$ years, respectively $(p=0.77)$. The BMI of women in OCPs group was

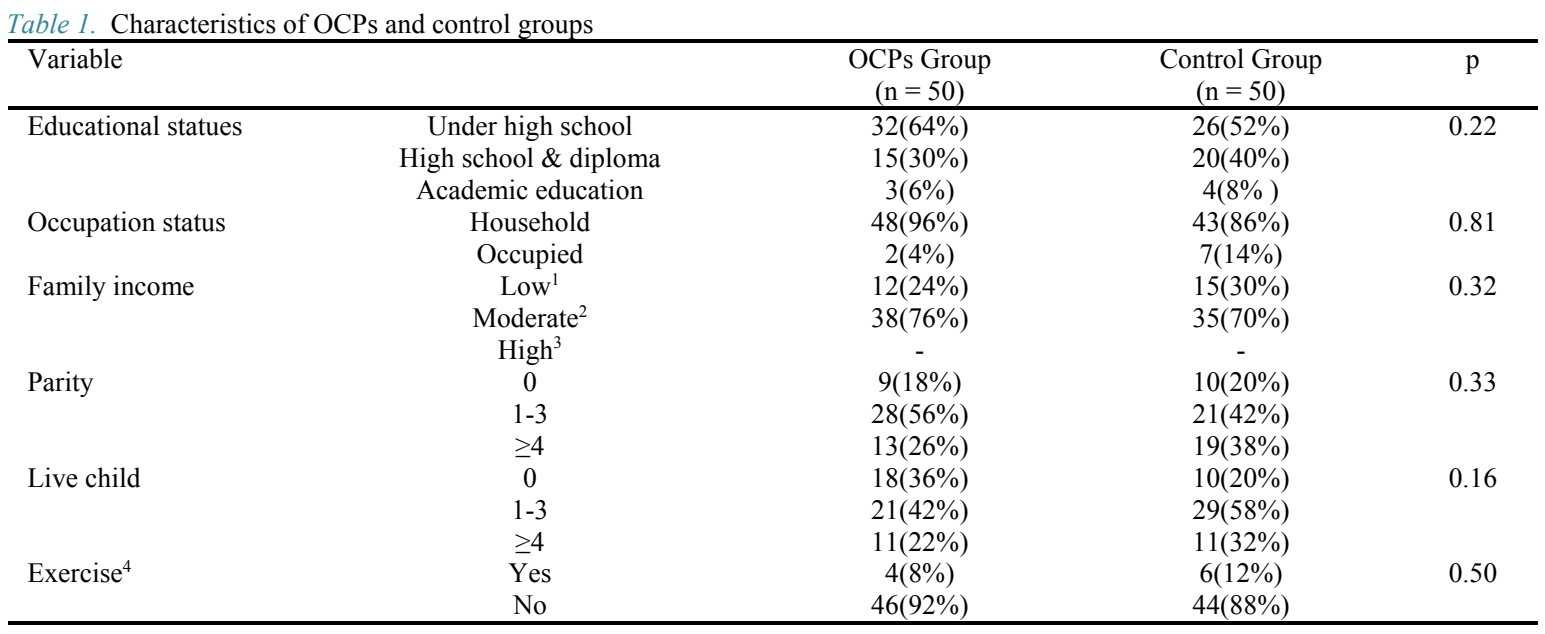


L. Amini, et al.

Table 2. Comparison of DAS28 clinical and laboratory parameters between the study groups before and after intervention

\begin{tabular}{|c|c|c|c|c|c|c|c|}
\hline \multirow[t]{2}{*}{ Parameter } & \multicolumn{3}{|c|}{ Before } & \multicolumn{3}{|c|}{ After } & \multirow[b]{2}{*}{$\mathrm{ES}^{*}$} \\
\hline & $\begin{array}{l}\text { OCPs group } \\
(\mathrm{M} \pm \mathrm{SD})\end{array}$ & $\begin{array}{l}\text { Control group } \\
(\mathrm{M} \pm \mathrm{SD})\end{array}$ & $\mathrm{p}$ & $\begin{array}{l}\text { OCPs group } \\
(\mathrm{M} \pm \mathrm{SD})\end{array}$ & $\begin{array}{l}\text { Control group } \\
(\mathrm{M} \pm \mathrm{SD})\end{array}$ & $\mathrm{p}$ & \\
\hline Swollen joints score & $2.1(0.42)$ & $1.4(0.22)$ & 0.10 & $1.3(0.25)$ & $2.2(0.31)$ & 0.02 & 2.19 \\
\hline Joint tenderness score & $3.02(0.52)$ & $2.4(0.31)$ & 0.06 & $2.2(0.41)$ & $3.7(0.48)$ & 0.02 & 2.12 \\
\hline ESR & $25.9(2.9)$ & $19.8(2.09)$ & 0.09 & $22.6(2.30)$ & $22.08(2.20)$ & 0.87 & 1.11 \\
\hline General health & $5.9(0.27)$ & $5.4(0.29)$ & 0.23 & $3.7(0.25)$ & $5.9(0.28)$ & 0.001 & 4.82 \\
\hline Total score of DAS28 & $3.94(1.13)$ & $3.58(1.07)$ & 0.10 & $3.35(1.00)$ & $3.78(1.23)$ & 0.04 & 0.33 \\
\hline \multicolumn{8}{|l|}{ *Effect size } \\
\hline \multirow[t]{2}{*}{ Disease activity classification } & \multicolumn{3}{|c|}{ Before } & & \multicolumn{2}{|c|}{ After } & \\
\hline & & roup & $\begin{array}{c}\text { Control group } \\
\mathrm{N}(\%)\end{array}$ & $\bar{p}$ & $\begin{array}{c}\text { OCPs group } \\
\mathrm{N}(\%)\end{array}$ & $\begin{array}{c}\text { Control group } \\
\mathrm{N}(\%)\end{array}$ & $\mathrm{p}$ \\
\hline Mild (DAS<3.2) & & & $20(40 \%)$ & & $26(52 \%)$ & $15(30 \%)$ & \\
\hline Moderate $(3.2 \leq \mathrm{DAS} \leq 5.1)$ & & & $26(52 \%)$ & & $21(42 \%)$ & $29(58 \%)$ & \\
\hline Sever $(\mathrm{DAS}>5.1)$ & & & $4(8 \%)$ & 0.10 & $3(6 \%)$ & $6(12 \%)$ & 0.04 \\
\hline
\end{tabular}

$28.12 \pm 4.97 \mathrm{~kg} / \mathrm{m}^{2}$ and it was $26.88 \pm 4.73 \mathrm{~kg} / \mathrm{m}^{2}$ in the control group $(\mathrm{p}=0.22)$. Women in OCPs and control groups were affected by RA for $9.00 \pm 6.94$ and $8.72 \pm 7.05$ years, respectively $(\mathrm{p}=0.19)$, and they received RA drugs for $8.72 \pm 7.05$ and $7.90 \pm 5.58$ years, respectively $(p=0.80)$. Table 1 demonstrates some characteristics of the participants in the study.

According to Table 2, the 2 study groups did not have any significant differences in DAS28 parameters or the total score before the intervention. After intervention, swollen joints score $(\mathrm{p}=0.02)$, joint tenderness score $(\mathrm{p}=0.02)$, general health $(\mathrm{p}<0.001)$, and DAS28 total score $(p=0.04)$ in OCPs were significantly lower than the control group, but ESR did not show any significant differences between the 2 groups.

According to severity of disease activity (DA), the comparison of mean $\pm \mathrm{SD}$ of DA severity in each group before and after the study revealed a significant DA reduction $(3.94 \pm 1.13$ vs. $3.35 \pm 1.00$, respectively) in OCPs group ( $\mathrm{p}=0.001)$ but not in the controls $(3.58 \pm 1.07$ vs. $3.79 \pm 1.22$ respectively). As demonstrated in Table 3 , there were no significant differences between the 2 study groups before the intervention; however, after the intervention, DA severity was significantly different between the 2 groups, as most women in the OCPs group (52\%) had mild DA severity and those in the control group $(58 \%)$ had moderate severity $(\mathrm{p}=0.04)$.

Neither of the 50 women who participated in the OCPs group complained of OCP side effects.

\section{Discussion}

The main goal of this study was to examine the effect of oral contraceptive pills (OCPs), which contain both estrogen and progesterone, on rheumatoid arthritis disease activity. The results revealed that OCPs can improve and reduce the severity of rheumatoid arthritis (RA) activity in women of reproductive age with RA according to the 28joint DAS. This can be due to the belief that sex hormones may contribute to the rheumatoid arthritis (RA) activity because of their role in the immune system response, as estrogens can enhance humoral system reactions and androgens and progesterone can suppress the immune system (15). Some believe that hormonal imbalance occurs in women with RA, and thus production or action of estrogens and androgens will be impaired. These changes can regulate RA onset, severity, and progression $(16,17)$. Nevertheless, the effect of OCPs on RA is not clear and there are many controversies surrounding the issue (18) because people respond differently to hormones. Although there are several studies about the role of OCPs in RA development, it is not clear whether OCPs can prevent or postpone RA. Recent studies have not shown any significant relationship between hormone replacement therapy (HRT) and RA (19). Similarly, Pikwer et al. (2009) indicated that there is not any association between having a history of OCPs and rheumatoid arthritis risk reduction (20). On the other hand, Jorgensen et al. (1996) found that using OCPs can protect against rheumatoid arthritis (21). Moreover, Cutolo et al. (2010) showed that androgens and steroid alternatives can adjust inflammatory status of joint tissue because sex hormones balance is a fundamental regulator of immune system and inflammatory reactions $(11,12)$. A study showed OCPs can reduce mild RA development in women who used OCPs for more than 5 years without any significant effect on long- term outcome of RA (22).

RA is likely to improve during pregnancy; thus, estrogen therapy or using OCPs can be suggested for younger women with RA, as they can benefit from noncontraceptive effects of OCPs (23). Also, a preventive effect against RA is proposed for oral contraceptive pills, and this effect is exerted by estrogens as a modulator in the immune system. Sapir-Koren and Livshits (2016) believe that steroid and androgenic hormones can be applied as a noteworthy therapeutic modulator for rheumatoid arthritis (24). Oral contraceptive pills can improve RA even before the RA symptoms emerge. Camacho et al. (2011) suggest that using OCPs before or around the symptom onset may propose long-lasting advantages (25).

One of our limitations in the present study was that as our participants used OCPs as a contraceptive method, we could not use placebo due to the risk of unwanted pregnancy. Besides, we did not assess the long- term effect of OCPs in women with RA due to time limitation.

\section{Conclusion}

Family planning is one of the most important concerns 
for women of reproductive age. Oral contraceptive pills are not only good contraceptive methods but also, according to our results, these pills can improve RA activity in affected women. Thus, it seems that these women can benefit from OCPs more than others.

The results of the present study support those of previous studies that found positive effects of OCPs on RA severity and activity.

\section{Acknowledgement}

This paper was extracted from an MSc thesis in midwifery and was financially supported by Tehran University of Medical Sciences, Tehran, Iran.

\section{Conflict of Interests}

The authors declare that they have no competing interests.

\section{References}

1. Fauci A, Langford C, Langford CA, Harrison's Rheumatology, Second Edition, McGraw-Hill Prof Med/Tech, May 18, 2010 - 368.

2. Kelly WN, Harris ED Jr, and Ruddy S, Sledge CB (Eds): Textbook of Rheumatology, Philadelphia: 10th Ed, WB Saunders 2017.

3. Qi S, Xin R, Guo W and Liu Y. Meta-analysis of oral contraceptives and rheumatoid arthritis risk in women. Ther Clin Risk Manage. 2014;4(10):15-23.

4. Chen Qi, Jin Z, Xiang c, Cai Q, Shi W, He J. Absence of protection effect of oral contraceptive use on the development of rheumatoid arthritis: a meta-analysis of observational studies. Int J Rheum Dis. 2014;17(7):725-37.

5. Salaffi F, Carotti M, Gasparini S, Intorcia M, Grassi W. The healthrelated quality of life in rheumatoid arthritis, ankylosing spondylitis, and psoriatic arthritis: a comparison with a selected sample of healthy people. Health Qual Life Outcom. 2009 Mar 18;7:25.

6. Louati K, Berenbaum F. Fatigue in chronic inflammation - a link to pain pathways. Louati Berenbaum Arthrit Res Therap. 2015;17:254.

7. Doran MFI, Crowson CS, Ofallon WM, Gabriel SE. The effect of oral contraceptives and estrogen replecment therapy on the risk of rheumatoid arthritis: a population based study. J Rheumatol. 2004; 31(2):207-13

8. Brouwer J, Laven JSE, Hazes JMW, Dolhain RJEM. Miscarriages in Female Rheumatoid Arthritis Patients: Associations with Serologic Findings, Disease Activity, and Antirheumatic Drug Treatment. Arthrit Rheumatol. 2015;67(7):1738-43.

9. Albrecht K, Callhoff J, Buttgereit F, Straub RH, Westhoff G, Zink A. Association between the use of oral contraceptivesband patientreported outcomes in an early arthritis cohort. Arthritis Care Res (Hoboken). 2016;63(3):400-5.

10. Farr SL, Folger SG, Paulen ME, Curtis KM. Safety of contraceptive methods for women with rheumatoid arthritis: a systematic review. Contraception. $2010 \mathrm{Jul}$; 82(1):64-71.

11. Cutolo M, Brizzolara R, Atzeni F, Capellino S, Straub RH, Puttini PC. The immunomodulatory effects of estrogens: clinical relevance in immune-mediated rheumatic diseases. Ann N Y Acad Sci. 2010 Apr;1193:36-42.

12. Cutolo M, Seriolo B, Villaggio B, Pizzorni C, Craviotto C, Sulli A. Androgens and estrogens modulate the immune and inflammatory responses in rheumatoid arthritis. Ann N Y Acad Sci. 2002 Jun; 966:131-42.

13. Walitt B, Pettinger M, Weinsteing A, katz J, Torner J, Wasko CH. Effects of Postmenopausal Hormone Therapy on Rheumatoid Arthritis: The Women's Health Initiative Randomized Controlled Trials. Arthrit Rheum. 2008;59(3):302-310

14. Smolen JS, Breedveld FC, Eberl G, Jones I, Leeming M, Wylie GL, et al. Validity and reliability of the twenty-eight-joint count for the assessment of rheumatoid arthritis activity. Arthrit Rheum. 1995 Jan;38(1):38-43

15. Cutolo M, Villaggio B, Craviotto C, Pizzorni C, Seriolo B, Sulli A. Sex hormones and rheumatoid arthritis. Autoimmun Rev. 2002;1(5):284-9.
16. Kanik KS, Wilder RL. Hormonal alterations in rheumatoid arthri tis, including the effects of pregnancy. Rheum Dis Clin North Am. 2000;26(4):805-23.

17. Ghamarzad Shishavan N, Pirouzpanah S, Hajialilo M, Khabbazi A, Jafarpour F, Mirtaheri E, et al. Risk Factors of Rheumatoid Arthritis Development Among Females in North-West of Iran: A CaseControl Study. Iran Red Crescent Med J. 201618(12):e26874.

18. Colangelo K, Haig S, Bonner A, Zelenietz C, Pope J. Self-reported flaring varies during the menstrual cycle in systemic lupus erythematosus compared with rheumatoid arthritis and fibromyalgia. Rheumatology. 2011;50:703-8.

19. Oliver JE, Silman AJ. Why are women predisposed to autoimmune rheumatic diseases? Arthritis Res Ther. 2009;11(5):252.

20. Pikwer M, Bergström U, Nilsson JA, Jacobsson L, Berglund G, Turesson C. Breast feeding, but not use of oral contraceptives, is associated with a reduced risk of rheumatoid arthritis. Ann Rheum Dis. 2009;6(4):526-30.

21. Jorgensen C, Picot MC, Bologna C, Sany J. Oral contraception, parity, breast feeding, and severity of rheumatoid arthritis. Ann Rheum Dis. 1996 Feb;55(2):94-8

22. Schindler AE. Non-Contraceptive Benefits of Oral Hormonal Contraceptives. Int J Endocrinol Metab. 2013;11(1):41-7.

23. Van Vollenhoven RF, McGuire JL. Estrogen, progesterone, and testosterone: can they be used to treat autoimmune diseases? Cleve Clin J Med. 1994;61(4):276-84.

24. Sapir-Koren R, Livshits G. Rheumatoid arthritis onset in postmenopausal women: Does the ACPA seropositive subset result from genetic effects, estrogen deficiency, skewed profile of CD4b T-cells, and their interactions? Molecul Cell Endocrinol. 2016;431:145e163.

25. Camacho EM, Lunt M, Farragher TM, Verstappen SMM, Bunn DK, Symmons DPM. The Relationship between Oral Contraceptive Use and Functional Outcome in Women with Recent-Onset Inflammatory Polyarthritis. Arthrit Rheum. 2011;63(8):2183-91. 